Article

\title{
Insights into the Pyrolysis Processes of Ce-MOFs for Preparing Highly Active Catalysts of Toluene Combustion
}

\author{
Wenjie Sun ${ }^{\circledR}$, Xiaomin $\mathrm{Li}^{\circledR}$, Chao Sun, Zhen Huang, Hualong $\mathrm{Xu}$ and Wei Shen * \\ Department of Chemistry, Shanghai Key Laboratory of Molecular Catalysis and Innovative Materials and \\ Laboratory of Advanced Materials, Collaborative Innovation Center of Chemistry for Energy Materials, Fudan \\ University, Shanghai 200433, China \\ * Correspondence: wshen@fudan.edu.cn; Tel.: +86-21-3124-2401
}

Received: 15 July 2019; Accepted: 7 August 2019; Published: 10 August 2019

\begin{abstract}
Metal organic frameworks (MOFs) have recently been used as precursors of the catalysts for the combustion of volatile organic compounds (VOCs). In the present work, three kinds of $\mathrm{CeO}_{2}$ catalysts were successfully synthesized from Ce-MOF-808, Ce-BTC, and Ce-UiO-66, with specific topological structures and coordinate environments. Catalysts with small particle size, stacking mode, and structural defects could be created by pyrolysis of Ce-MOFs, which affects the activity in the toluene combustion significantly. Raman spectra, XPS, and OSC studies were performed to reveal the formation of defect sites. The thermal redox properties were determined by $\mathrm{H}_{2}$-TPR. Catalytic activity tests were conducted on the toluene combustion, and $\mathrm{CeO}_{2}-\mathrm{MOF}-808$ showed the best catalytic performance $\left(\mathrm{T} 90=278^{\circ} \mathrm{C}\right)$ due to its having the largest specific surface area, abundant active surface oxygen species, and low-temperature reducibility.
\end{abstract}

Keywords: Ce-MOF; cerium oxide; catalytic combustion of toluene; environmental catalysis; pyrolysis process

\section{Introduction}

Recently, air pollution has received much attention because of the adverse effects for health and the environment $[1,2]$. Volatile organic compounds (VOCs) are one of the main culprits leading to air pollution, and the spread of VOCs into the atmosphere will give rise to photochemical smog and secondary aerosols [3]. As a representative VOC, toluene has been widely investigated as a model compound for reducing pollution of the environment. Several technologies such as adsorption, biological degradation, and catalytic oxidation have been developed to control toluene emission $[4,5]$. Among these, catalytic combustion is considered one of the most efficient methods for the elimination of toluene [6,7].

The Mars-Van Krevelen (MvK) mechanism is used to describe how toluene is oxidized to water and carbon dioxide with the oxide catalysts. Two main redox steps are included in the mechanism: (1) the reactive species oxidize toluene to water and carbon dioxide, (2) the oxygen in the gas oxidizes the surface of the oxides [8]. Thus, the transitional metal oxides which can provide activated oxygen species such as $\mathrm{CuO}_{x}, \mathrm{CoO}_{x}, \mathrm{MnO}_{\mathrm{x}}$, and $\mathrm{CeO}_{\mathrm{x}}$ [9-11] have proved to be efficient catalysts for toluene combustion. Among them, ceria plays an important role due to its unique properties and the high abundance of oxygen in the lattice. Ceria-based catalysts have wide applications in water gas shift reaction [12], $\mathrm{NH}_{3}$ selective catalytic reduction $\left(\mathrm{NH}_{3}-\mathrm{SCR}\right)$ [13], catalytic elimination of $\mathrm{N}_{2} \mathrm{O}$, and so on [14], due to their controllable morphological characteristics, high oxygen storage capacity, and abundant oxygen vacancies. For toluene catalytic combustion, the synthesis strategy will affect the morphology and 
lattice defects of ceria, and influence the active sites for the reaction [15]. Nanostructured ceria cubes and rods have demonstrated the importance of the concentration of surface oxygen defects for toluene combustion [16]. Hu et al. prepared a chestnut-like $\mathrm{CeO}_{2}$ catalyst using a self-assembly method [17]. The porous structure consisted of nanowire hierarchical microspheres, which provided a large surface area and surface oxygen vacancies, leading to the increased catalytic performance for toluene catalytic oxidation. The improved catalytic activity demonstrated the importance of structural regulation, and also indicated the possibility of further catalytic activity improvement by enhancing the defective sites.

Metal organic frameworks (MOFs) are compounds with regular structures consisting of metal clusters and ligands. In recent decades, great quantities of MOFs have been synthesized and applied in various fields [18]. Co-, Mn-, and Ce-MOFs have been synthesized and calcined to obtain the corresponding oxides for the catalytic combustion of VOCs $[19,20]$. Benefiting from the three-dimensional mesoporous structure formed by pyrolysis of MOFs, ceria catalysts showed good activity. After calcination, the morphology of $\mathrm{Ce}-\mathrm{MOF}$ as a precursor, had a positive effect on the adsorption and desorption of toluene, enhancing catalytic activity [21]. $\mathrm{CeO}_{2}$ synthesized with Ce-BTC as the hard template was reported to have better activity and stability, compared with commercial ceria [22]. Ce-MOF-808 and Ce-UiO-66 show similarly stable structures as Ce-BTC. Meanwhile, precursors with more abundant pores and simple means of preparation could be candidates for preparing highly active ceria catalysts.

In this paper, three kinds of MOFs were synthesized as precursors of catalysts. To investigate the effects of the structure and ligands of Ce-MOFs on the structural properties of ceria through the pyrolysis process, various techniques were applied to determine the distinctions between the physical and chemical characteristics among these catalysts. The catalytic evaluation of the oxide catalysts was performed by the catalytic combustion of toluene.

\section{Results and Discussion}

\subsection{Preparation of Ce-MOFs and the Pyrolysis Process}

\subsubsection{Structural Analysis of Ce-MOFs}

To investigate the pyrolysis processes of Ce-MOFs, the Ce-MOFs including Ce-MOF-808, Ce-BTC, and $\mathrm{Ce}-\mathrm{UiO}-66$ were chosen as precursors for the catalyst synthesis. Ce-BTC consists of Ce atoms, water molecules, and 1,3,5-benzenetricarboxylic acid ( $\mathrm{H}_{3}$-BTC). The composition of Ce-MOF-808 is similar to that of Ce-BTC with the main difference being the $\mathrm{Ce}_{6}$ clusters as the secondary building units. $\mathrm{Ce}-\mathrm{UiO}-66$ has the same $\mathrm{Ce}_{6}$ clusters as Ce-MOF-808 but involves a different ligand, 1,4-dicarboxybenzene $\left(\mathrm{H}_{2}-\mathrm{BDC}\right)$. The structures of these three kinds of Ce-MOFs are shown in Figure 1. The space groups of Ce-MOF-808, Ce-BTC, and Ce-UiO-66 are $F d-3 m, C c$, and $F m-3 m$, respectively [23-25]. Through powder X-ray diffraction (PXRD), the purity and crystallinity of the Ce-MOFs were verified, as shown in Figure 2. The XRD patterns of Ce-MOFs were also simulated based on the Cambridge Crystallographic Data Centre (CCDC) database. The CCDC codes for Ce-MOF-808 and Ce-UiO-66 are CCDC 1509776 and CCDC 1036904, respectively. An isostructural MOF, La-BTC $\left(\mathrm{La}(\mathrm{BTC})\left(\mathrm{H}_{2} \mathrm{O}\right)_{6}\right)(\mathrm{CCDC} 290771)$ was used to simulate Ce-BTC. The background of the experimental result was deducted for comparison. The peak positions of the experimental results were consistent with the simulated patterns. The differences between the experimental and simulated patterns were due to the preferred orientation, systematic absences, and the crystal defects. 


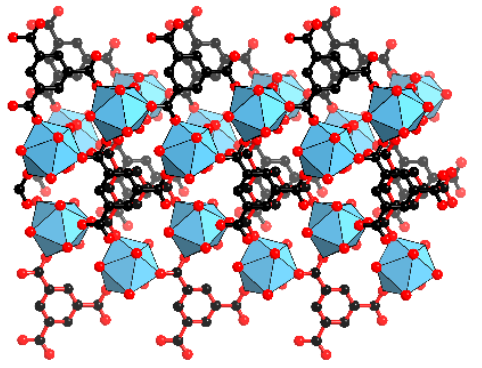

(a)

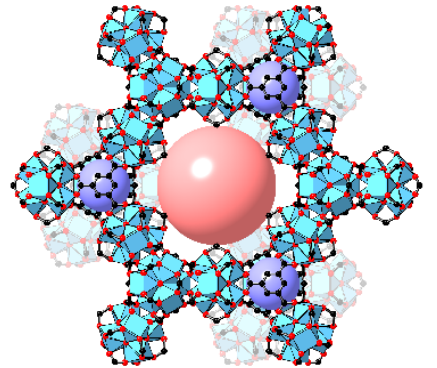

(b)

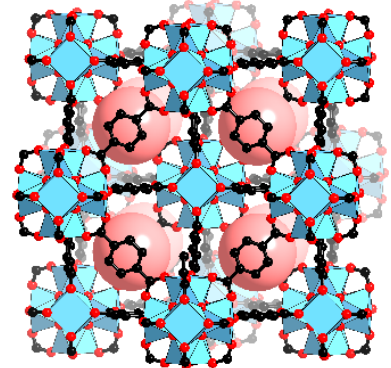

(c)

Figure 1. The structural diagrams of (a) Ce-BTC, (b) Ce-MOF-808, and (c) Ce-UiO-66. Blue polyhedron: Ce cluster; red ball: O; black ball: C; pink and violet ball: pore.

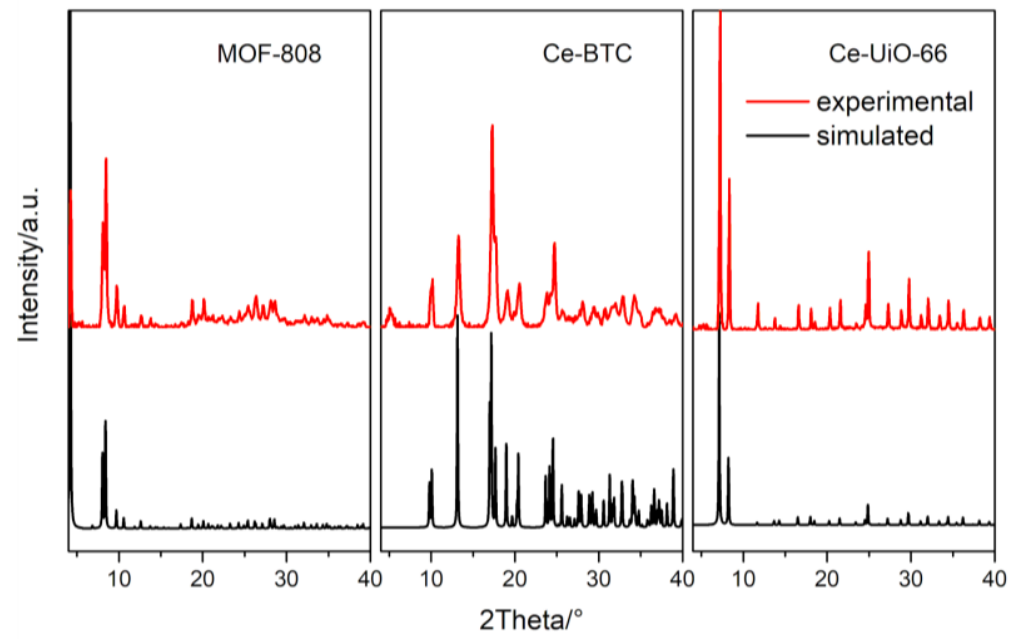

Figure 2. The PXRD patterns for the Ce-MOFs.

Transmission electron microscopy (TEM) images of the MOFs (Figure 3) were used to determine the morphologies before calcination. Ce-MOF-808 and Ce-UiO-66 both formed particle shapes while Ce-BTC displayed regular stick morphology, as presented. Compared with Ce-MOF-808, Ce-UiO-66 had a more regular shape and relatively larger crystallite dimension.

The textural properties were calculated based on the $\mathrm{N}_{2}$ adsorption/desorption measurements, as listed in Table 1. It was shown that before pyrolysis, Ce-MOF-808 and Ce-UiO-66 exhibited large specific surface areas of 469.4 and $425.0 \mathrm{~m}^{2} / \mathrm{g}$, respectively, while Ce-BTC possessed a specific surface area of $28.9 \mathrm{~m}^{2} / \mathrm{g}$ with small micropores [26]. The specific surface area values of Ce-MOF-808 and $\mathrm{Ce}-\mathrm{UiO}-66$ were lower than those previously reported $[23,25]$. The decrease of the specific surface areas may be caused by the structural defects, which were related to the scale up synthesis of the MOFs. The micropore widths of Ce-MOF-808 and Ce-UiO-66 were consistent with those already reported.

Table 1. The surface properties of Ce-MOFs.

\begin{tabular}{ccccc}
\hline & $\begin{array}{c}\text { Specific Surface } \\
\text { Area }\left(\mathbf{m}^{\mathbf{2}} \mathbf{g}\right)\end{array}$ & $\begin{array}{c}\text { Micropore Area } \\
\left(\mathbf{m}^{2} / \mathbf{g}\right)\end{array}$ & $\begin{array}{c}\text { Micropore } \\
\text { Volume }\left(\mathbf{c m}^{\mathbf{3}} / \mathbf{g}\right)\end{array}$ & $\begin{array}{c}\text { Micropore Width } \\
(\mathbf{n m})\end{array}$ \\
\hline Ce-MOF-808 & 469.4 & 350.4 & 0.182 & 1.948 \\
Ce-BTC & 28.9 & - & - & - \\
Ce-UiO-66 & 425.0 & 234.3 & 0.126 & 1.022 \\
\hline
\end{tabular}




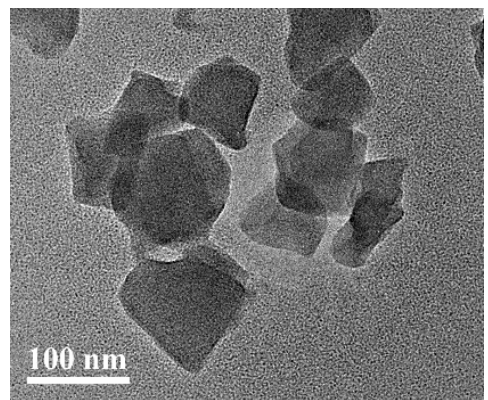

(a1)

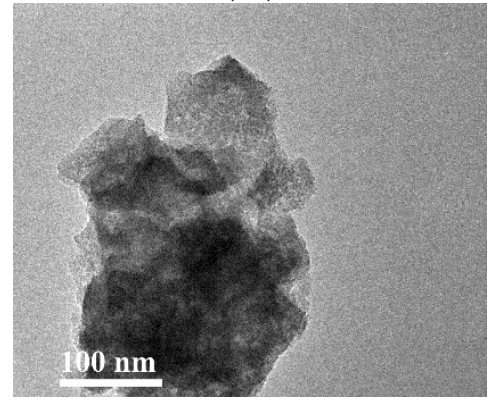

(a2)

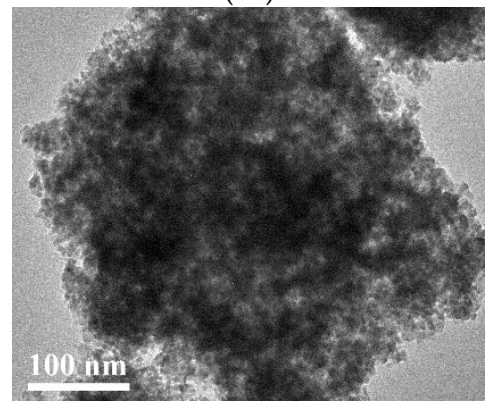

(a3)

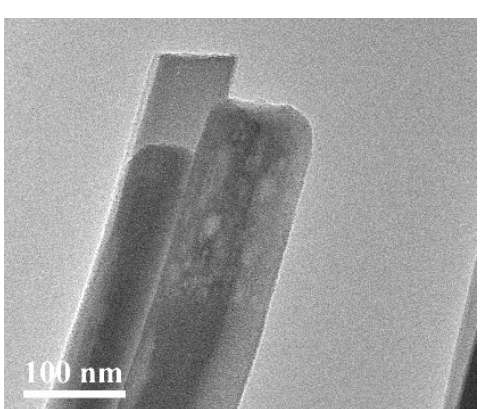

(b1)

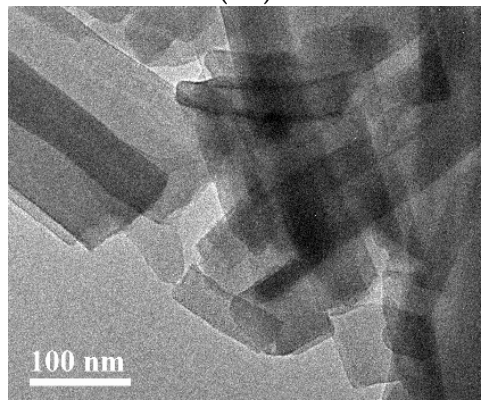

(b2)

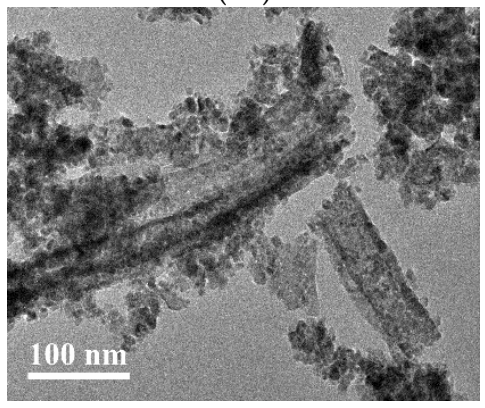

(b3)

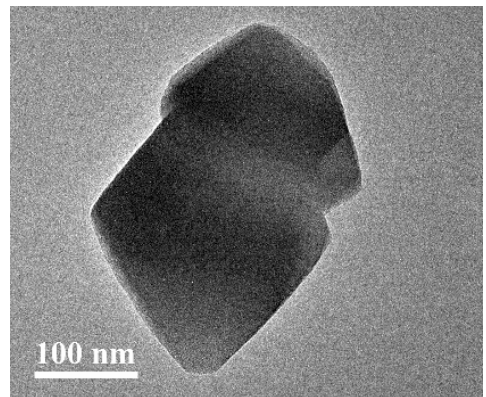

(c1)

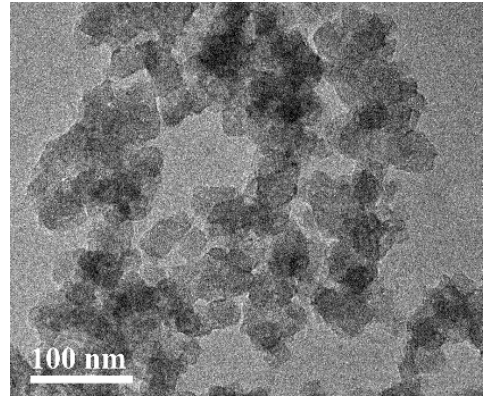

(c2)

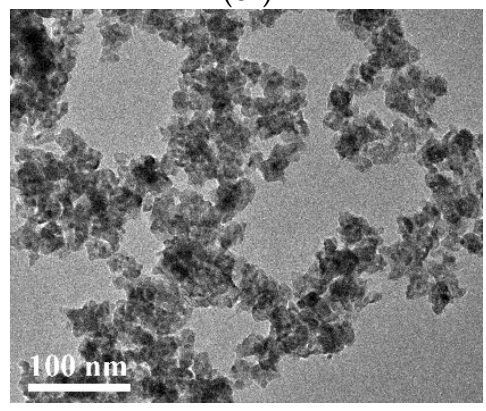

(c3)

Figure 3. TEM images of Ce-MOF-808, Ce-BTC, and Ce-UiO-66 before calcination (a1, b1, c1); Ce-MOF-808-250, Ce-BTC-340, and Ce-UiO-66-320 after calcination at $250{ }^{\circ} \mathrm{C}, 340{ }^{\circ} \mathrm{C}$, and $320{ }^{\circ} \mathrm{C}$ respectively $(\mathbf{a} 2, \mathbf{b 2}, \mathbf{c 2})$; and the corresponding final $\mathrm{CeO}_{2}-\mathrm{MOFs}$ after calcination at $500{ }^{\circ} \mathrm{C}(\mathbf{a} 3, \mathbf{b} 3, \mathbf{c} 3)$.

\subsubsection{Changes in the Structures and Surface Morphologies upon Calcination}

Weight losses of the samples were evaluated using thermal gravimetric analysis (TGA), as depicted in Figure 4. The first weight loss stage of the three samples below $150{ }^{\circ} \mathrm{C}$ was assigned to the removal of water molecules. For Ce-MOF-808 and Ce-UiO-66, the weight loss at this stage is mainly caused by adsorbed water. The coordination bond of the water molecule in Ce-BTC leads to a higher removal temperature. During the second stage, between $150{ }^{\circ} \mathrm{C}$ and $322^{\circ} \mathrm{C}$, the sample underwent slow decomposition, from $10 \%$ to $14.5 \%$, releasing $\mathrm{N}, \mathrm{N}$-dimethylformamide (DMF), part of coordinate water, and formic acid ligands [27]. The third stage of weight loss links to the Ce-MOFs decomposition. Ce-MOF-808, Ce-BTC, and Ce-UiO-66 exhibited rapid weight loss of $24.3 \%, 35.8 \%$, and $34.0 \%$ to form $\mathrm{CeO}_{2}$ at $311^{\circ} \mathrm{C}, 378^{\circ} \mathrm{C}$, and $334^{\circ} \mathrm{C}$, respectively. In addition, a temperature of $500^{\circ} \mathrm{C}$ was found to be enough to remove all the organic frameworks and form cerium oxides. 


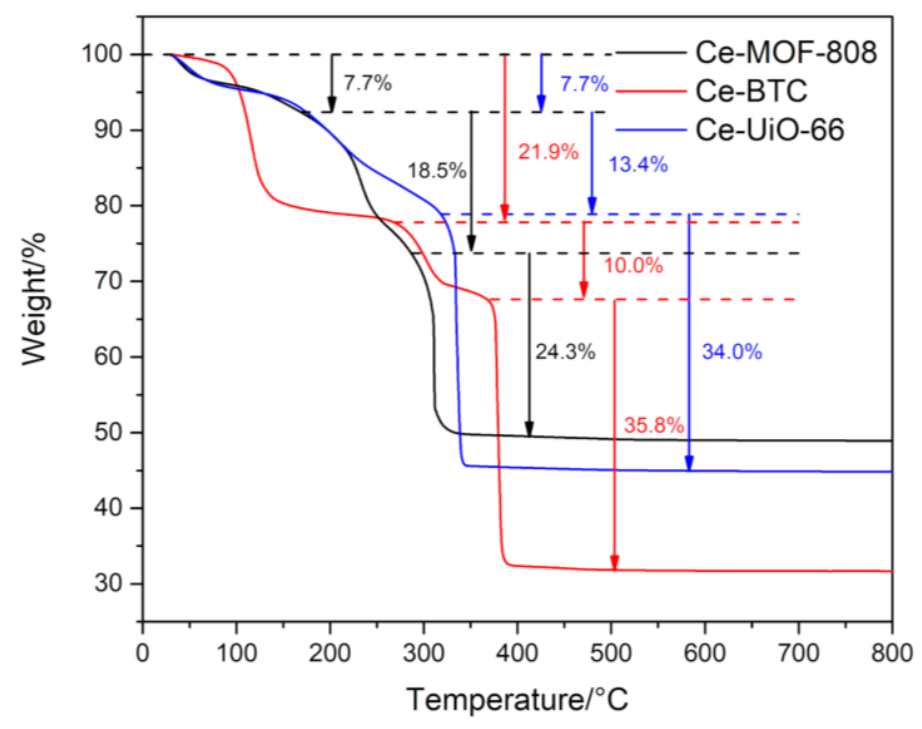

Figure 4. The TGA profiles of the Ce-MOFs.

The samples derived from Ce-MOF-808, Ce-BTC, and Ce-UiO-66 after calcination at $500{ }^{\circ} \mathrm{C}$, are denoted as $\mathrm{CeO}_{2}-\mathrm{MOF}-808, \mathrm{CeO}_{2}-\mathrm{BTC}$, and $\mathrm{CeO}_{2}-\mathrm{UiO}-66$. The detailed crystalline changes were explored by PXRD measurements within the pyrolysis temperature range from $200{ }^{\circ} \mathrm{C}$ to $400{ }^{\circ} \mathrm{C}$, during which the crystalline phase of the catalyst changed significantly, as shown in Figure 5. For MOFs, the lattice parameters led to strong diffraction peaks at low angles while there is no diffraction peak at low angle for the cerium oxides. As the calcination temperature increased, the structures of Ce-MOFs transformed into ceria. A clear phase transition occurred between $200{ }^{\circ} \mathrm{C}$ and $300{ }^{\circ} \mathrm{C}$ in MOF-808, while for the other two, it occurred at a higher temperature of between $300{ }^{\circ} \mathrm{C}$ and $350{ }^{\circ} \mathrm{C}$. For MOF-808, from $220^{\circ} \mathrm{C}$, no obvious peaks were observed until the temperature reached $290^{\circ} \mathrm{C}$, accompanied by the appearance of the characteristic peaks for ceria at $2 \theta=28^{\circ}$. For Ce-BTC, the characteristic diffraction band at $11.2^{\circ}$ maintained at $340^{\circ} \mathrm{C}$, while the peaks attributed to ceria began to appear at $330^{\circ} \mathrm{C}$. This indicated that $\mathrm{Ce}-\mathrm{BTC}$ and $\mathrm{CeO}_{2}$ co-existed in its calcination process. Ceria formed before the carbon burned out in the structure. The calcination process is obviously different for Ce-UiO- 66 which holds a well-defined structure up to $300^{\circ} \mathrm{C}$. At the calcination temperature of $310^{\circ} \mathrm{C}$, the crystallinity of Ce-UiO-66 decreased significantly, and then almost no peaks were found at $320^{\circ} \mathrm{C}$, which means that the MOFs structures collapsed and carbon-coated compounds or a tiny number of ceria particles were formed. When the temperature increased to a higher level, a well-crystallized ceria phase was formed. During calcination, the phase transition from Ce-UiO-66 to $\mathrm{CeO}_{2}-\mathrm{UiO}-66$ was much faster than those of other Ce-MOFs. Meanwhile, there was no similar state of coexistence of two species in the Ce-BTC calcination process. This suggests that, apart from Ce-UiO-66, the destruction of the other two MOFs' structures partly coincided with the formation of $\mathrm{CeO}_{2}$ in the whole calcination process, which imposes a positive impact on the formation of the $\mathrm{CeO}_{2}$ structure and the maintenance of particle size. 


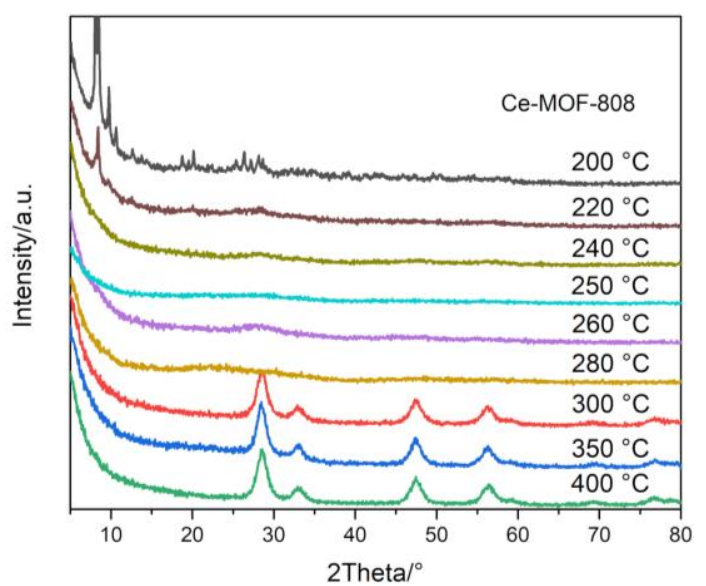

(a)

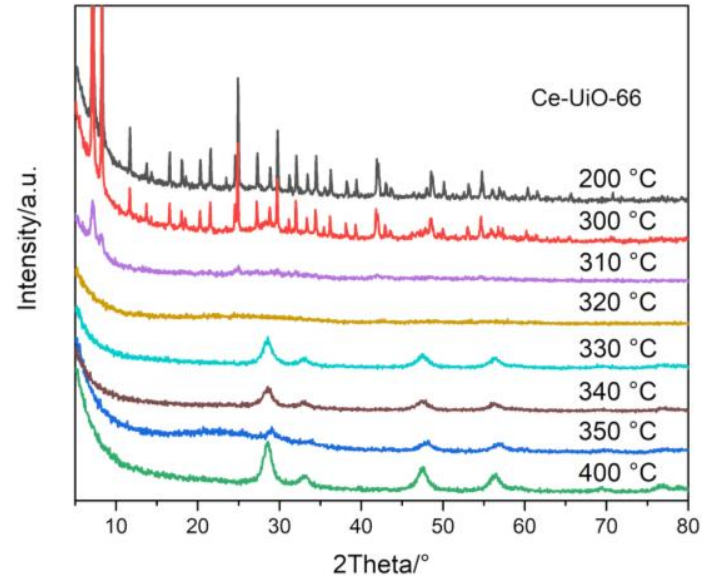

(c)

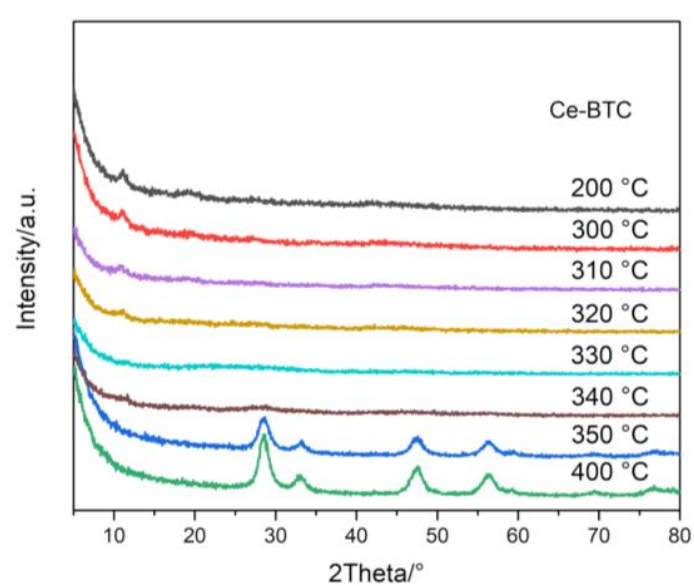

(b)

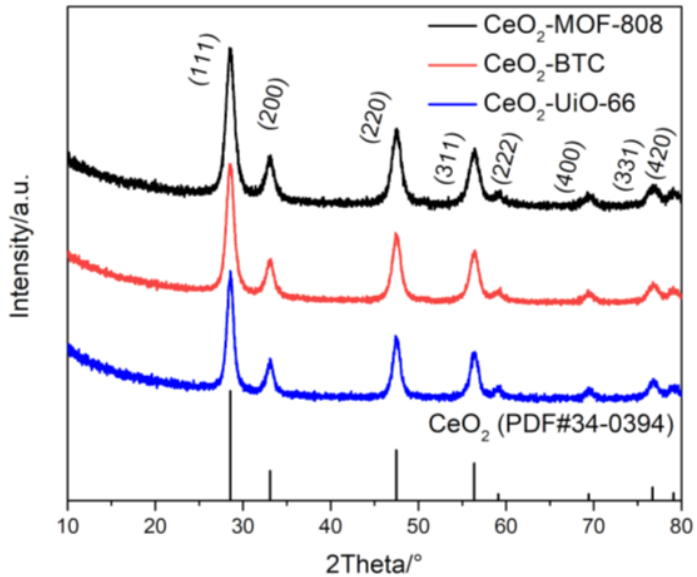

(d)

Figure 5. The PXRD patterns of (a) Ce-MOF-808, (b) Ce-BTC, and (c) Ce-UiO-66 at different temperatures, and (d) the $\mathrm{CeO}_{2}-\mathrm{MOF}$ after calcination at $500{ }^{\circ} \mathrm{C}$.

Considering the structural effects of the MOFs skeleton on the final structure of ceria, samples calcined at critical temperatures were observed by TEM in Figure 3. According to the PXRD measurements at different temperatures, Ce-MOF-808 at $250{ }^{\circ} \mathrm{C}, \mathrm{Ce}-\mathrm{BTC}$ at $340{ }^{\circ} \mathrm{C}$, and Ce-UiO-66 at $320{ }^{\circ} \mathrm{C}$ were selected as the crucial samples with amorphous phases, and named Ce-MOF-808-250, Ce-BTC-340, and Ce-UiO-66-320, respectively. It is very important to observe the amorphous phase transition to trace the calcination process. At the selected pyrolysis temperatures, Ce-MOF-808 and Ce-BTC samples retained their MOF frameworks, while highly dispersed particles began forming in the Ce-UiO-66-320. For Ce-MOF-808-250 and Ce-BTC-340, the overall morphology and structure showed little change, while small particles (small dots with deeper contrast) were being formed, which may indicate the nucleation process of ceria. For Ce-UiO-66-320, the particle size obviously decreased, compared with that of the sample before calcination. The dimension of these particles was slightly larger than those of $\mathrm{CeO}_{2}-\mathrm{UiO}-66$ samples obtained by complete calcination. This indicates that at this temperature, the burning of ligands results in the formation of smaller particles, and then the pyrolysis process proceeds based on these small particles. This phenomenon supports the PXRD results, which confirms that the particle sizes and stacking forms of the oxide products are greatly affected by the way ligands are removed from the MOFs' skeleton during calcination.

\subsubsection{Structural Analysis of $\mathrm{CeO}_{2}-\mathrm{MOF}$}

The PXRD patterns of ceria samples are shown in Figure $5 \mathrm{~d}$. After calcination at $500{ }^{\circ} \mathrm{C}$, all the Ce-MOFs formed cubic ceria crystals, showing peaks at $28.6^{\circ}, 33.1^{\circ}, 47.5^{\circ}, 56.3^{\circ}, 59.1^{\circ}, 79.4^{\circ}, 76.7^{\circ}$, 
and $79.1^{\circ}$ respectively, corresponding to the facets (111), (200), (220), (311), (222), (400), (331), and (420). The positions of the characteristic peaks were consistent with a fluorite structure (JCPDS Card No. 34-0394). The average particle sizes of $\mathrm{CeO}_{2}-\mathrm{MOF}-808, \mathrm{CeO}_{2}-\mathrm{BTC}$, and $\mathrm{CeO}_{2}-\mathrm{UiO}-66$ were about $5.3 \mathrm{~nm}, 9.7 \mathrm{~nm}$, and $10.6 \mathrm{~nm}$, as listed in Table 2. Based on the results of the previous calcination process and the PXRD patterns, the crystallinity of $\mathrm{CeO}_{2}-\mathrm{UiO}-66$ was relatively higher, and fewer defect sites might have been created on its surface than the others.

Table 2. The surface properties and catalytic performance of $\mathrm{CeO}_{2}-\mathrm{MOFs}$.

\begin{tabular}{|c|c|c|c|c|c|c|}
\hline & $\begin{array}{l}\text { Particle Size } \\
\text { (nm) }{ }^{a}\end{array}$ & $\begin{array}{l}\text { Particle Size } \\
(\text { nm) })^{b}\end{array}$ & $\begin{array}{l}\text { Specific Surface } \\
\text { Area }\left(\mathrm{m}^{2} / \mathrm{g}\right)\end{array}$ & $\mathbf{I}_{\mathbf{D}} / \mathbf{I}_{\mathbf{F} 2 \mathrm{~g}}$ & $\begin{array}{c}\mathrm{Ce}^{3+} /\left(\mathrm{Ce}^{3+}+\mathrm{Ce}^{4+}\right) \\
(\%)\end{array}$ & $\begin{array}{c}\mathrm{O}_{\text {sur }} / \mathrm{O}_{\text {latt }} \\
(\%)\end{array}$ \\
\hline $\mathrm{CeO}_{2}-\mathrm{MOF}-808$ & 5.2 & 6.7 & 96.6 & 0.035 & 25.4 & 46.8 \\
\hline $\mathrm{CeO}_{2}-\mathrm{BTC}$ & 9.7 & 9.8 & 71.5 & 0.026 & 24.4 & 36.8 \\
\hline $\mathrm{CeO}_{2}-\mathrm{UiO}-66$ & 10.6 & 11.1 & 38.8 & 0.018 & 19.1 & 30.2 \\
\hline
\end{tabular}

Figure 3 shows the morphologies of the $\mathrm{CeO}_{2}-\mathrm{MOFs}$ characterized by TEM after calcination. $\mathrm{CeO}_{2}$-MOF-808 and $\mathrm{CeO}_{2}$-BTC show aggregation of small particles, while $\mathrm{CeO}_{2}$-UiO-66 disperses into uniform small particles. Stacked structures are more likely to form defective surfaces. The existence of interfaces between the small particles increased lattice disorder and produced more defective surfaces, which are essential for efficient catalysts [28]. The particle sizes of these three cerium oxides were calculated, by counting, to be $6.7 \mathrm{~nm}, 9.8 \mathrm{~nm}$, and $11.1 \mathrm{~nm}$ for $\mathrm{CeO}_{2}-\mathrm{MOF}-808, \mathrm{CeO}_{2}-\mathrm{BTC}$, and $\mathrm{CeO}_{2}-\mathrm{UiO}-66$, respectively. These numbers are more or less the same as those calculated from PXRD. The scanning electron microscope (SEM) images of the samples during the calcination are provided in Figure S1. The SEM images show that during calcination, Ce-UiO-66 changed its shape from uniform particles to small pieces, while the other two underwent slight changes.

The specific surface areas of ceria prepared by MOFs precursor were calculated by the Brunauer-Emmett-Teller (BET) method and are listed in Table 2. The specific surface areas of MOF-808 and UiO-66 decreased greatly to 96.6 and $38.8 \mathrm{~m}^{2} / \mathrm{g}$, respectively, while that of Ce-BTC increased to $71.5 \mathrm{~m}^{2} / \mathrm{g}$. The increase of the Ce-BTC surface area was due to the formation of a porous structure after calcination [26].

\subsubsection{Proposed Mechanism of the Pyrolysis Processes}

As shown by the above characterization, the pyrolysis processes were significantly different for the three MOFs, as presented in Scheme 1. For Ce-MOF-808, the coexistence of carbon skeleton and ceria was maintained for a long time in the calcination process. At a relatively low temperature $\left(250^{\circ} \mathrm{C}\right)$, the MOFs structures were destroyed to form a carbon skeleton as a support. This state lasted over a relatively long temperature range until the carbon was further burned to $\mathrm{CO}_{2}$, and then the ceria particles were formed. Because of the different ligands, the frameworks of Ce-UiO- 66 first broke into smaller pieces during calcination. Then, structural changes of $\mathrm{Ce}-\mathrm{UiO}-66$ were more rapid so that the residual carbon burned out soon after the frameworks collapsed into pieces. Overall, the pyrolysis of Ce-MOF-808 and Ce-BTC were more similar to each other than to Ce-UiO-66. The absence of a carbon skeleton is beneficial to forming a final catalyst with smaller particle size, higher specific surface area, and more defect sites. Next, we focused on the characterization of these oxides and how the calcination process affected the surface composition and the structural defects. These play a crucial role in the catalytic combustion of toluene. 


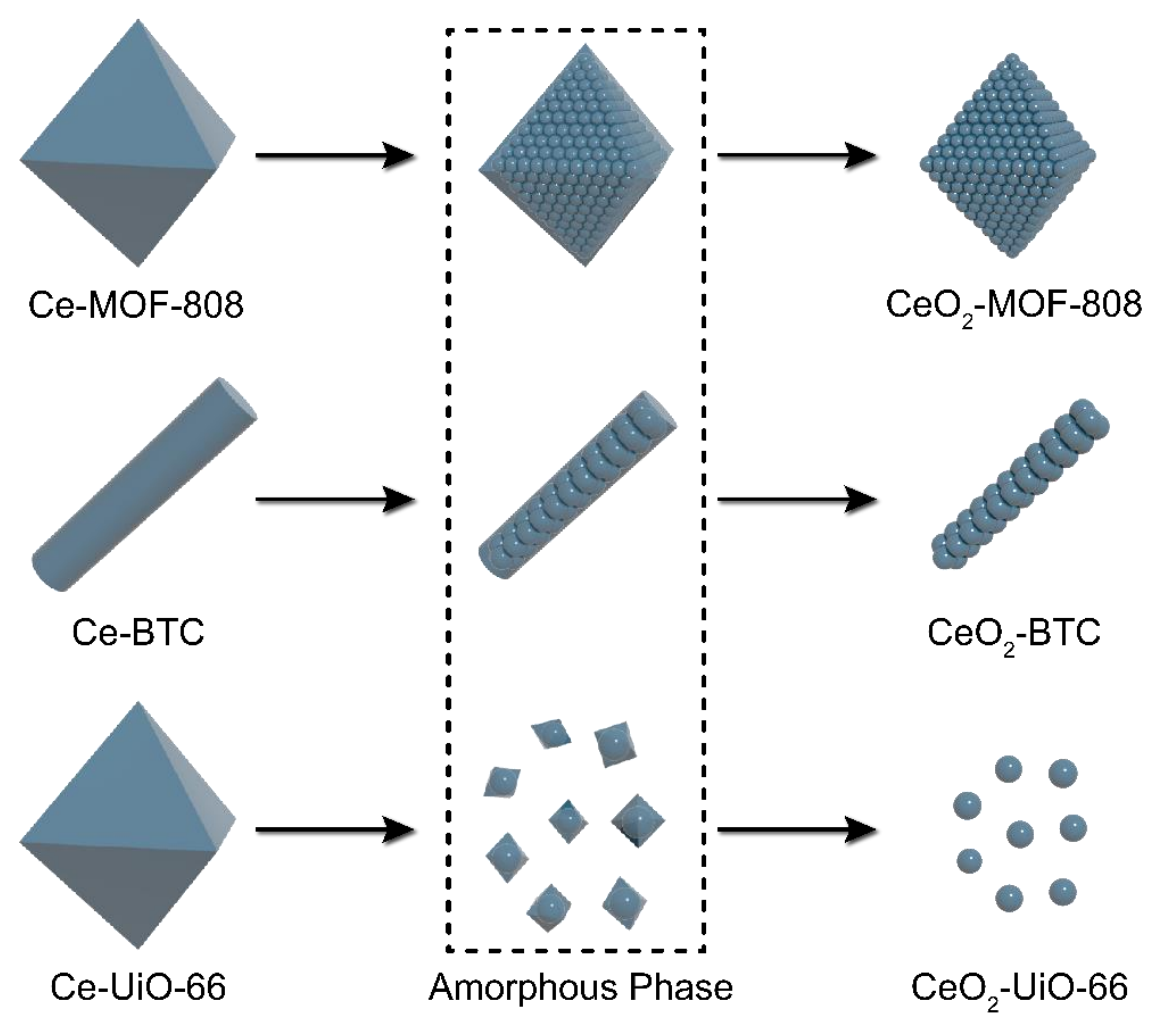

Scheme 1. Presentation of the roasting processes of three metal organic frameworks (MOFs).

\subsection{Characterization of $\mathrm{CeO}_{2}-\mathrm{MOFs}$}

\subsubsection{Surface Composition of $\mathrm{CeO}_{2}-\mathrm{MOFs}$}

Raman spectra were obtained to reveal the defect sites of the samples, as shown in Figure 6a. The strongest vibration peak at $460 \mathrm{~cm}^{-1}$ is attributed to the symmetric stretching $\left(\mathrm{F}_{2 \mathrm{~g}}\right)$ vibration mode in the cubic fluorite ceria [29]. As shown in the magnified inset (Figure 6a), peaks centered at ca. $600 \mathrm{~cm}^{-1}$ are observed, corresponding to the defect-induced (D) vibration mode. The intensity of the $\mathrm{D}$ mode peaks has a linear correlation with the amount of oxygen vacancies, which are caused by the existence of $\mathrm{Ce}^{3+}$ [30]. Accordingly, the ratio of the intensities of $\mathrm{D}$ mode and $\mathrm{F}_{2 \mathrm{~g}}$ mode peaks $\left(\mathrm{I}_{\mathrm{D}} / \mathrm{I}_{\mathrm{F} 2 \mathrm{~g}}\right)$ can be regarded as an effective indicator for the relative concentration of the oxygen vacancies. As shown in Table 1, the sequence of the values of $\mathrm{I}_{\mathrm{D}} / \mathrm{I}_{\mathrm{F} 2 \mathrm{~g}}$ was as follows: $\mathrm{CeO}_{2}-\mathrm{MOF}-808(0.035)>$ $\mathrm{CeO}_{2}$-BTC (0.026) $>\mathrm{CeO}_{2}$-UiO-66 (0.018). The lattice disorders, rather than the particle sizes, influenced the $\mathrm{I}_{\mathrm{D}} / \mathrm{I}_{\mathrm{F} 2 \mathrm{~g}}$ ratio [31]. Since there were more small grains of Ce-MOF-808 and Ce-BTC overlapping each other than those of Ce-UiO-66, the calcination process affected not only the grain sizes, but also the structural defects of the crystals. Samples with larger specific surface areas and more intrinsic defect sites more easily produced abundant oxygen defects for the catalytic deep oxidation. 


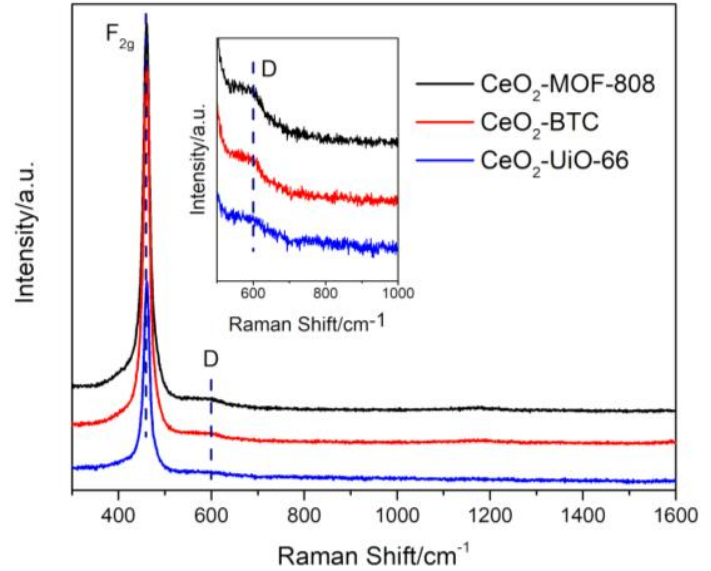

(a)

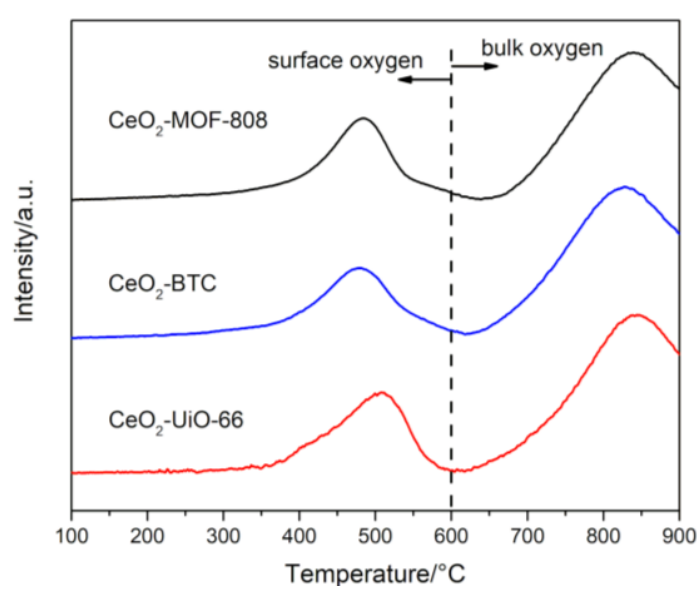

(b)

Figure 6. (a) The Raman curves of $\mathrm{CeO}_{2}-\mathrm{MOF}$ and (b) the $\mathrm{H}_{2}-\mathrm{TPR}$ of $\mathrm{CeO}_{2}-\mathrm{MOFs}$.

The element contents and the valence states of elements on the surface of $\mathrm{CeO}_{2}-\mathrm{MOF}$ were analyzed by X-ray photoelectron spectroscopy (XPS). The surface O1s and Ce3d spectra of three $\mathrm{CeO}_{2}$ samples are shown in Figure 7. By deconvoluting the peaks of O1s spectra at the binding energies of 529-530 eV, 530-531 eV, and 533-534 eV, the contents of adsorbed oxygen on the surface, lattice oxygen on the surface, and bulk lattice oxygen (marked as $\mathrm{O}_{\text {ads }}, \mathrm{O}_{\text {sur, }}$ and $\mathrm{O}_{\text {latt, }}$, respectively) could be obtained [22,32,33]. Several kinds of active oxygen species such as peroxide species $\left(\mathrm{O}^{-}\right)$and superoxide species $\left(\mathrm{O}^{2-}\right)$ are included in $\mathrm{O}_{\text {sur. }} \cdot \mathrm{CeO}_{2}-\mathrm{MOF}-808$ demonstrated a ratio of $\mathrm{O}_{\text {sur }} / \mathrm{O}_{\text {latt }}$ of $46.8 \%$, which was much higher than the other two. The ratio of oxygen on the surface of ceria has a significant correlation with its catalytic activity, as a higher ratio of $\mathrm{O}_{\text {sur }} / \mathrm{O}_{\text {latt }}$ leads to stronger catalytic deep oxidation ability.

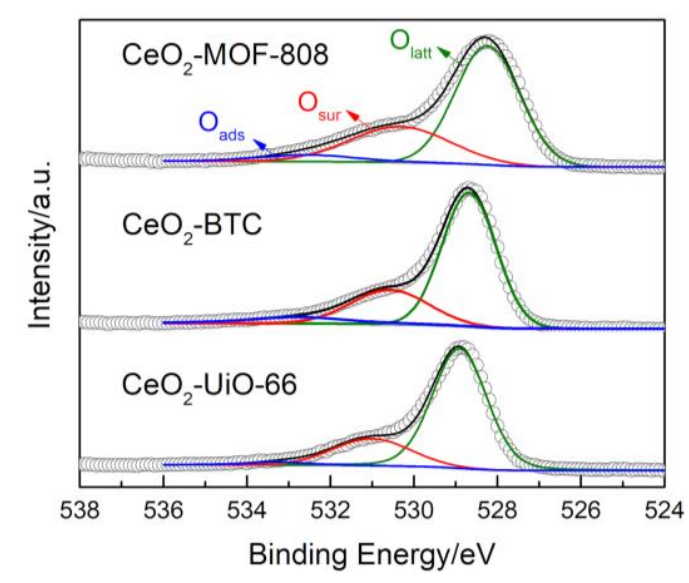

(a)

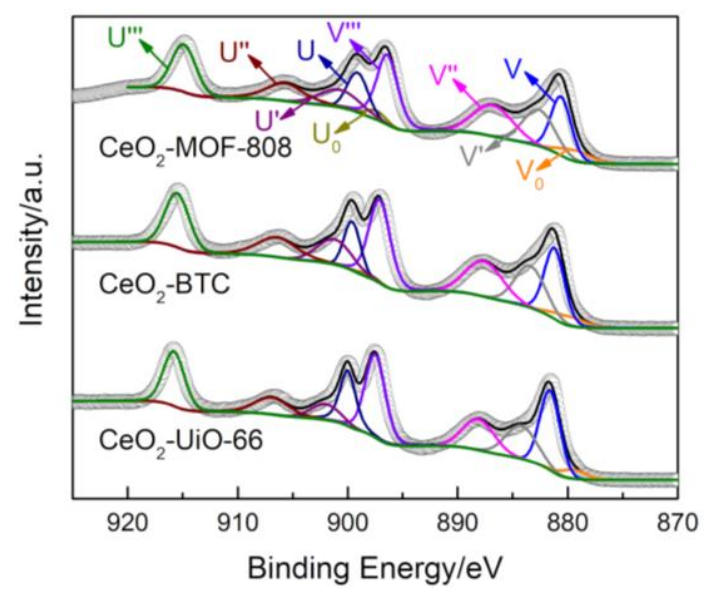

(b)

Figure 7. The surface (a) $\mathrm{O} 1 \mathrm{~s}$ and (b) $\mathrm{Ce} 3 \mathrm{~d}$ spectra of three $\mathrm{CeO}_{2}-\mathrm{MOF}$ samples.

A distinction between $\mathrm{Ce}^{3+}$ and $\mathrm{Ce}^{4+}$ was also made by separating the Ce3d peaks. Ten peaks were divided according to the binding energy and were marked as $\mathrm{V}_{0}, \mathrm{~V}, \mathrm{~V}^{\prime}, \mathrm{V}^{\prime \prime}, \mathrm{V}^{\prime \prime \prime}, \mathrm{U}_{0}, \mathrm{U}^{\prime} \mathrm{U}^{\prime}, \mathrm{U}^{\prime \prime}$, and $U^{\prime \prime \prime}$, from lowest to highest. Peaks labeled with $V$ and $U$ were ascribed to $C e 3 d_{3 / 2}$ and Ce $3 d_{5 / 2}$, respectively. Peaks assigned to $\mathrm{Ce}^{3+}$ included the four peaks $\mathrm{U}_{0}, \mathrm{U}^{\prime}, \mathrm{V}_{0}$, and $\mathrm{V}^{\prime}$, while the peaks assigned to $\mathrm{Ce}^{4+}$ included the other six peaks $\mathrm{U}, \mathrm{U}^{\prime \prime}, \mathrm{U}^{\prime \prime \prime}, \mathrm{V}, \mathrm{V}^{\prime \prime}$, and $\mathrm{V}^{\prime \prime \prime}$. The order of the ratios of $\mathrm{Ce}^{3+} /\left(\mathrm{Ce}^{3+}+\mathrm{Ce}^{4+}\right)$ was $\mathrm{CeO}_{2}-\mathrm{MOF}-808>\mathrm{CeO}_{2}-\mathrm{BTC}>\mathrm{CeO}_{2}-\mathrm{UiO}-66$. The presence of $\mathrm{Ce}^{3+}$ suggests the loss of oxygen in stoichiometric $\mathrm{CeO}_{2}$, which is related to the oxygen vacancies [34]. The order of 
$\mathrm{Ce}^{3+}$ proportions exhibited was in accordance with the sequence of oxygen defects calculated by the Raman analysis.

\subsubsection{Oxygen Storage Capacity (OSC) and Reducibility of $\mathrm{CeO}_{2}-\mathrm{MOFs}$}

OSC was employed to quantify the amount of stored oxygen species. $\mathrm{CeO}_{2}-\mathrm{MOF}-808$ possessed $514 \mu \mathrm{mol}\left(\mathrm{O}_{2}\right) / \mathrm{g}(\mathrm{cat})$, while the OSC values of $\mathrm{CeO}_{2}-\mathrm{BTC}$ and $\mathrm{CeO}_{2}-\mathrm{UiO}-66$ were $488 \mu \mathrm{mol}\left(\mathrm{O}_{2}\right) / \mathrm{g}(\mathrm{cat})$ and $118 \mu \mathrm{mol}\left(\mathrm{O}_{2}\right) / \mathrm{g}$ (cat), respectively. Compared with $\mathrm{CeO}_{2}-\mathrm{UiO}-66, \mathrm{CeO}_{2}-\mathrm{MOF}-808$ and $\mathrm{CeO}_{2}-\mathrm{BTC}$ had higher OSC values, which means that more molecular oxygen in these two is likely to be involved in the catalytic combustion [35].

The redox properties of $\mathrm{CeO}_{2}-\mathrm{MOFs}$ were assessed by $\mathrm{H}_{2}$-temperature programmed reduction $\left(\mathrm{H}_{2}-\mathrm{TPR}\right)$, as shown in Figure $6 \mathrm{~b}$. There are two peaks located around $500{ }^{\circ} \mathrm{C}$ and $840{ }^{\circ} \mathrm{C}$, which stand for the reduction of surface oxygen and bulk oxygen, respectively. The lower the temperature at which the reduction peaks are located, the stronger the reducibility of the catalyst surface. Since the surface oxygen takes part in the reaction directly, the reduction peaks at low temperatures $\left(<600^{\circ} \mathrm{C}\right)$ were investigated. $\mathrm{CeO}_{2}-\mathrm{MOF}-808$ and $\mathrm{CeO}_{2}-\mathrm{BTC}$ showed almost the same reducibility with reduction signals at $482{ }^{\circ} \mathrm{C}$ and $480{ }^{\circ} \mathrm{C}$, respectively, significantly lower than that of $\mathrm{CeO}_{2}-\mathrm{UiO}-66\left(508^{\circ} \mathrm{C}\right)$.

\subsection{Catalytic Performance Evaluation of $\mathrm{CeO}_{2}-\mathrm{MOFs}$ on Toluene Oxidation}

\subsubsection{Catalytic Performance of the $\mathrm{CeO}_{2}-\mathrm{MOFs}$ for Toluene Oxidation}

The catalytic activities of $\mathrm{CeO}_{2}-\mathrm{MOF}$ were assessed by catalytic combustion of toluene. The test results are shown in Figure 8a. T50 and T90, the temperatures for 50\% and 90\% conversion are important parameters to evaluate catalytic activity. $\mathrm{CeO}_{2}-\mathrm{MOF}-808$, which had the largest surface area, abundant defective sites, and great reducibility, showed the best performance with T50 and $\mathrm{T} 90$ at $218^{\circ} \mathrm{C}$ and $278{ }^{\circ} \mathrm{C}$, respectively. T50 and T90 of the other two ceria samples are also listed in Table 2, and the order of the ability for catalytic combustion of toluene is $\mathrm{CeO}_{2}-\mathrm{MOF}-808>\mathrm{CeO}_{2}-\mathrm{BTC}>$ $\mathrm{CeO}_{2}-\mathrm{UiO}-66 . \mathrm{CeO}_{2}-\mathrm{BTC}$ also formed a porous structure but had slightly lower activity because of its relatively larger particle size and lower density of defective sites. The catalyst with the worst catalytic performance was $\mathrm{CeO}_{2}-\mathrm{UiO}-66$, which is related to the formation of larger dispersed particles after pyrolysis. For comparison, the catalytic performance of the transition metal oxides derived from MOFs are listed in Table 3. Among these oxides, the $\mathrm{T} 50$ value for $\mathrm{CeO}_{2}-\mathrm{MOF}-808$ is the lowest when the gas hourly space velocity (GHSV) is no less than $60,000 \mathrm{~mL} /(\mathrm{g} \cdot \mathrm{h})$ ). Since $\mathrm{CeO}_{2}-\mathrm{MOF}-808$ performed the best among these three catalysts, the combustion activity of toluene at different space velocities was also tested. With the increase of GHSV from 30,000 to 120,000 mL/(g.h), T50 and T90 over $\mathrm{CeO}_{2}-\mathrm{MOF}-808$ were similar, from 30,000 to $60,000 \mathrm{~mL} /(\mathrm{g} \cdot \mathrm{h})$, while the conversion of toluene decreased obviously at a GHSV of $120,000 \mathrm{~mL} /(\mathrm{g} \cdot \mathrm{h})$. This indicates that the active sites of $\mathrm{CeO}_{2}-\mathrm{MOF}-808$ were enough for toluene combustion at low GHSV (GHSV $\leqq 60,000 \mathrm{~mL} /(\mathrm{g} \cdot \mathrm{h})$ ). 


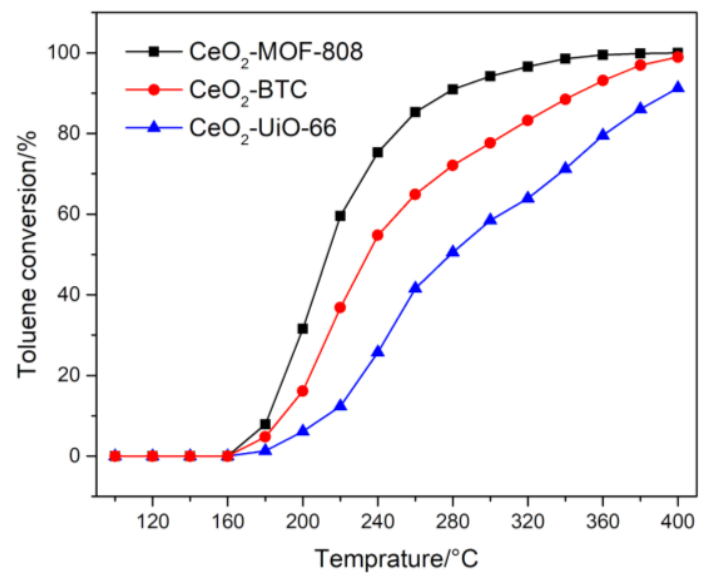

(a)

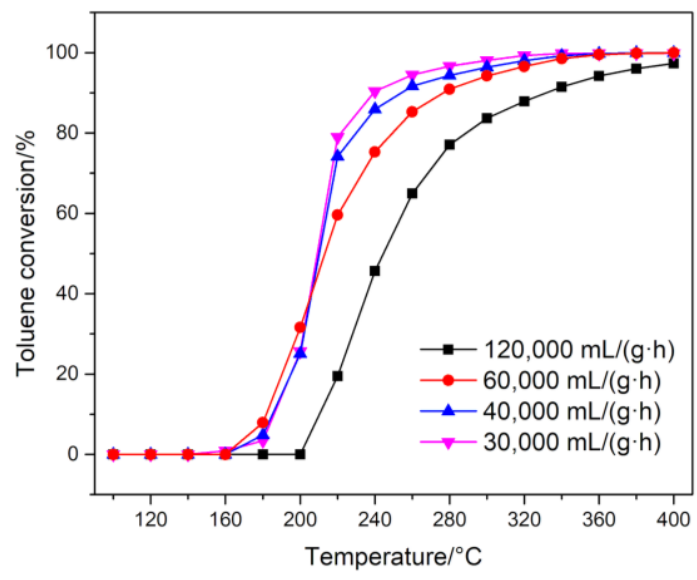

(b)

Figure 8. The combustion curves of $1000 \mathrm{ppm}$ toluene in air (a) catalyzed by $\mathrm{CeO}_{2}-\mathrm{MOF}$ at a GHSV of $60,000 \mathrm{~mL} /(\mathrm{g} \cdot \mathrm{h})$, and (b) for $\mathrm{CeO}_{2}-\mathrm{MOF}-808$ at different GHSV from 30,000 mL/(g.h) to 120,000 mL/(g.h).

Table 3. The catalytic performance of transition metal oxides derived from MOFs.

\begin{tabular}{ccccccc}
\hline Oxides & Precursor & T50 & T90 & Toluene Concentration & GHSV & Reference \\
\hline $\mathrm{CeO}_{2}$ & Ce-MOF-808 & 218 & 278 & 1000 & 60,000 & This work \\
$\mathrm{CeO}_{2}$ & Ce-BTC & 232 & 343 & 1000 & 60,000 & This work \\
$\mathrm{CeO}_{2}$ & Ce-UiO-66 & 280 & 392 & 1000 & 60,000 & This work \\
$\mathrm{CeO}_{2}$ & Ce-BTC & 211 & 223 & 1000 & 20,000 & Reference $[22]$ \\
& & 233 & 251 & & 120,000 & Reference [22] \\
$\mathrm{Co}-\mathrm{Mn}$ & Co-Mn-MOF & 226 & 240 & 500 & 96,000 & Reference $[20]$ \\
$\mathrm{Co}-\mathrm{Mn}$ & ZIF-74 & 232 & 248 & 1000 & 60,000 & Reference [19] \\
\hline
\end{tabular}

\subsubsection{Stability Tests of $\mathrm{CeO}_{2}$-MOFs}

The stability of these catalysts was evaluated at $260^{\circ} \mathrm{C}$, and the results are shown in Figure 9. In the 72-h test, a total amount of $432 \mathrm{~L}$ reaction gas containing $1000 \mathrm{ppm}$ toluene passed through the catalysts. There was little change in the catalytic activity over the $\mathrm{CeO}_{2}$ catalysts derived from $\mathrm{MOFs}$, which means the data for the catalytic performance are reliable. No organic by-product was detected during catalytic reaction and no carbonaceous deposition was observed after the test either. Therefore, we speculate that under reaction conditions, the physicochemical properties of the catalysts do not change significantly within the testing period.

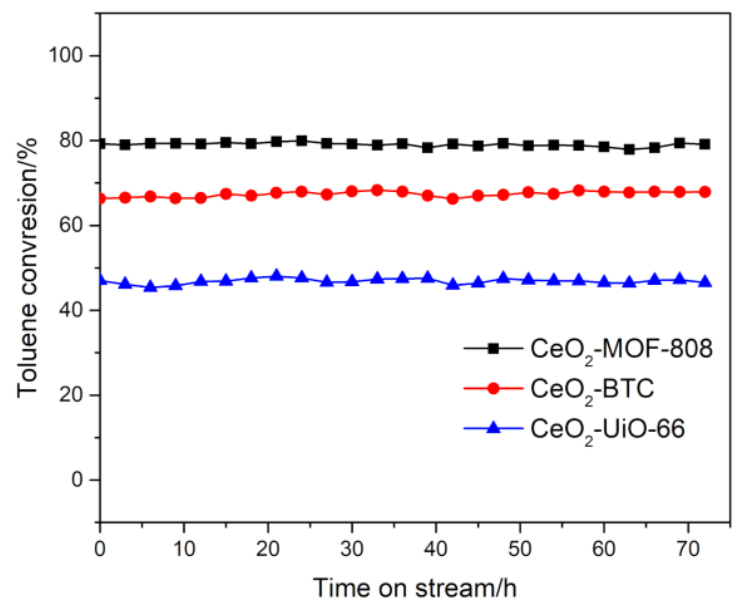

Figure 9. The stability test of the three ceria samples. Reaction conditions: toluene concentration: 1000 ppm; gas hourly space velocity (GHSV): 60,000 mL/(g.h); temperature: $260^{\circ} \mathrm{C}$. 


\section{Materials and Methods}

\subsection{Materials}

All the reagents were analytical grade and were used without further purification. 1,3,5-benzenetricarboxylic acid $\left(\mathrm{H}_{3}-\mathrm{BTC}, \mathrm{C}_{9} \mathrm{H}_{6} \mathrm{O}_{6}, 98 \%\right.$ ), $\mathrm{N}, \mathrm{N}$-dimethylformamide (DMF, $\mathrm{C}_{3} \mathrm{H}_{7} \mathrm{NO}$, $99.5 \%)$, formic acid $\left(\mathrm{CH}_{2} \mathrm{O}_{2}, 98 \%\right)$, cerium nitrate $\left(\mathrm{Ce}\left(\mathrm{NO}_{3}\right)_{3} \cdot 6 \mathrm{H}_{2} \mathrm{O}, 99 \%\right)$, ethanol $\left(\mathrm{CH}_{4} \mathrm{O}, 99.7 \%\right)$, and toluene $\left(\mathrm{C}_{7} \mathrm{H}_{8}, 99.5 \%\right)$ were purchased from Sinoreagent (Shanghai, China). Cerium (IV) ammonium nitrate $\left(\left(\mathrm{NH}_{4}\right)_{2} \mathrm{Ce}\left(\mathrm{NO}_{3}\right)_{6}, 99 \%\right)$ and 1,4-benzenedicarboxylic acid $\left(\mathrm{H}_{2}-\mathrm{BDC}, \mathrm{C}_{8} \mathrm{H}_{6} \mathrm{O}_{4}, 99 \%\right)$ were purchased from Aladdin (Shanghai, China). Deionized water was obtained by a water purification system (Super-Genie E, RephiLe Bioscience, Ltd., Shanghai, China).

\subsection{Synthesis of Three MOFs}

Ce-MOFs were synthesized by solvent thermal methods. The synthesis processes were based on the literature and scaled up for catalytic tests [23-25].

\subsubsection{Synthesis of Ce-MOF- 808}

To synthesize Ce-MOF-808, $\mathrm{H}_{3}$-BTC $(0.224 \mathrm{~g}, 1.06 \mathrm{mmol})$ was dissolved in $12 \mathrm{~mL}$ DMF in a $50 \mathrm{~mL}$ vial. An aqueous solution of $\left(\mathrm{NH}_{4}\right)_{2} \mathrm{Ce}\left(\mathrm{NO}_{3}\right)_{6}(6 \mathrm{~mL}, 0.533 \mathrm{M})$ was then added dropwise. $\mathrm{HCOOH}$ $(98 \%, 2.57 \mathrm{~mL}, 68.3 \mathrm{mmol})$ was added to the mixture at the same time, as a modulator. After the vial was sealed and heated isothermally at $100{ }^{\circ} \mathrm{C}$ for $15 \mathrm{~min}$, the suspension was centrifuged. Afterwards, Ce-MOF-808 powder was washed with $15 \mathrm{~mL}$ DMF three times and with $15 \mathrm{~mL}$ acetone three times, and then dried in a vacuum at $90^{\circ} \mathrm{C}$ overnight.

\subsubsection{Synthesis of Ce-BTC}

For the synthesis of Ce-BTC, two solutions containing $\mathrm{H}_{3}-\mathrm{BTC}\left(2.10 \mathrm{~g} \mathrm{H}_{3}-\mathrm{BTC}\right.$ dissolved in $10 \mathrm{~mL}$ $\mathrm{H}_{2} \mathrm{O}$ and $10 \mathrm{~mL}$ ethanol) and $\mathrm{Ce}\left(\mathrm{NO}_{3}\right)_{3}\left(4.34 \mathrm{~g} \mathrm{Ce}\left(\mathrm{NO}_{3}\right)_{3} \cdot 6 \mathrm{H}_{2} \mathrm{O}\right.$ dissolved in $\left.45 \mathrm{~mL} \mathrm{H}_{2} \mathrm{O}\right)$ were mixed together and heated with continuous stirring at $60^{\circ} \mathrm{C}$ for $1 \mathrm{~h}$. The white precipitate was centrifuged and washed with water and ethanol three times. After drying at $70^{\circ} \mathrm{C}$ overnight, Ce-BTC was obtained.

\subsubsection{Synthesis of Ce-UiO-66}

The synthesis process for Ce-UiO-66 was similar to the process for Ce-MOF-808. $\mathrm{H}_{2}-\mathrm{BDC}(0.531 \mathrm{~g}$, $3.20 \mathrm{mmol})$ was dissolved in $12 \mathrm{~mL}$ DMF in a $50 \mathrm{~mL}$ vial. $\left(\mathrm{NH}_{4}\right)_{2} \mathrm{Ce}\left(\mathrm{NO}_{3}\right)_{6}$ aqueous solution $(6 \mathrm{~mL}$, $0.533 \mathrm{M})$ was then added. After the vial was sealed, the heating conditions, the washing method, and the drying procedure were the same as those for MOF-808.

\subsection{Synthesis of $\mathrm{CeO}_{2}-\mathrm{MOFs}$}

The ceria derived from these MOF templates were obtained by calcination. To prevent severe pyrolysis of Ce-MOFs in the air, the heating rate was set at $2{ }^{\circ} \mathrm{C} / \mathrm{min}$. According to the TGA results, an appropriate calcination temperature was chosen to remove all the carbon. The Ce-MOFs above were heated at $500{ }^{\circ} \mathrm{C}$ and maintained for $4 \mathrm{~h}$ in the muffle furnace. Yellow powders were collected after cooling down. For catalytic tests, the oxides were compressed and crushed into pieces. Afterwards, 40-60 mesh particles were sifted.

\subsection{Characterization}

The powder X-ray diffractometer (PXRD, AXS D8, Bruker, Madison, WI, USA) equipped with Cu $\mathrm{K} \alpha$ radiation was operated to obtain the crystal structures and crystalline states. The increment and the rotation speed rate were set as $0.05^{\circ}$ and $12^{\circ} / \mathrm{min}$, respectively. The nitrogen adsorption/desorption tests of microporous samples (Ce-MOFs) were conducted with the automatic surface and micropore analyzer (ASAP 2020 Plus, Micromeritics, Norcross, GA, USA) at $77 \mathrm{~K}$. Mesoporous samples $\left(\mathrm{CeO}_{2}-\mathrm{MOF}\right.$ ) 
were tested by another machine (Tristar II 3020, Micromeritics, Norcross, GA, USA) under the same conditions. The Brunauer-Emmett-Teller (BET) method was used to calculate the specific surface area. The t-plot and the density functional theory (DFT) methods were employed to analyze the micropores. Thermogravimetric analysis (TGA, TGA8000, PerkinElmer, Waltham, MA, USA) was performed under air at the heating rate of $10^{\circ} \mathrm{C} / \mathrm{min}$ to record the mass change of the MOFs in the heating process. Transmission electron microscopy (TEM, JEM-2010, JEOL, Tokyo, Japan) and scanning electron microscopy (SEM, Phenom Prox, Phenom, Eindhoven, The Netherlands) were used to observe the morphology and the size of the samples. The analysis of the surface element and the valence states was conducted by X-ray photoelectron spectroscopy (XPS, Axis Ultra Dld, Kratos, Manchester, UK) with an $\mathrm{Al} \mathrm{K} \alpha$ source $(\mathrm{hv}=1486.6 \mathrm{eV}$ ). A chemisorption analyzer (Auto Chem II 2920, Micromeritics, Norcross, GA, USA) with a TPx system was used to record the data of the $\mathrm{H}_{2}$-temperature programmed reduction characteristic $\left(\mathrm{H}_{2}\right.$-TPR). After pretreatment in pure helium at the rate of $30 \mathrm{~mL} / \mathrm{min}$ at $300{ }^{\circ} \mathrm{C}$ for $30 \mathrm{~min}$, the samples were purged with $5 \% \mathrm{H}_{2} / \mathrm{He}$ gas. The temperature was ramped up at $10^{\circ} \mathrm{C} / \mathrm{min}$ from $50{ }^{\circ} \mathrm{C}$ to $900{ }^{\circ} \mathrm{C}$ and the hydrogen consumption was collected with a thermal conductivity detector. The oxygen storage capacity tests were also performed on the same chemisorption analyzer with $\mathrm{H}_{2}$-TPR. $5 \% \mathrm{H}_{2} / \mathrm{He}$ gas was used to reduce the samples at $300{ }^{\circ} \mathrm{C}$ for $1 \mathrm{~h}$ and then the samples cooled down with the protection of helium. $5 \% \mathrm{O}_{2} / \mathrm{He}$ pulses were introduced at $300{ }^{\circ} \mathrm{C}$ until the peak areas of the $\mathrm{O}_{2}$ TCD signals remained unchanged.

\subsection{Catalytic Performance}

Tests of the above catalytic performance were carried out in a flow fixed-bed reactor (length $=405 \mathrm{~mm}$, i.d. $=8 \mathrm{~mm}$ ) loading $100 \mathrm{mg}$ catalysts (40-60 mesh) mixed with $600 \mathrm{mg}$ quartz sand. A stream of high-purity air $\left(21 \% \mathrm{O}_{2}+79 \% \mathrm{~N}_{2}\right)$ flow passed through toluene at $2{ }^{\circ} \mathrm{C}$, maintained by a constant temperature water bath, and was then diluted by the other stream of high-purity air to obtain the reactant feed consisting of $1000 \mathrm{ppm}$ toluene and air. The total flow rate was set from $50 \mathrm{~mL} / \mathrm{min}$ to $200 \mathrm{~mL} / \mathrm{min}$ to obtain a GHSV of $30,000 \mathrm{~mL} /\left(\mathrm{g}_{\text {cat }} \cdot \mathrm{h}\right)$ to $120,000 \mathrm{~mL} /\left(\mathrm{g}_{\text {cat }} \cdot \mathrm{h}\right)$. For the catalytic comparative tests and durability tests, the GHSV was set as $60,000 \mathrm{~mL} /\left(\mathrm{g}_{\text {cat }} \cdot \mathrm{h}\right)$. The temperature for the test ranged from $100{ }^{\circ} \mathrm{C}$ to $400{ }^{\circ} \mathrm{C}$. After being maintained at a certain temperature for $30 \mathrm{~min}$, the outlet was introduced into an online Trace GC Ultra equipped with flame ionization detector (FID) and PLOT Q column. Possible organic by-products, such as benzaldehyde and benzoic acid, were not detected in the experiments.

The conversion of toluene was calculated by the following equation:

$$
\text { Conversion }=\frac{C_{\text {in }}-C_{\text {out }}}{C_{\text {in }}} \times 100 \%
$$

where $C_{\text {in }}$ and $C_{\text {out }}$ stand for the concentration of the inlet and outlet, respectively.

\section{Conclusions}

In summary, ceria samples derived from Ce-MOF-808, Ce-BTC, and Ce-UiO-66 have been synthesized and successfully applied in the catalytic combustion of toluene. The temperatures at which the organic frameworks transform to carbon and then the carbon skeletons burn out, are determined by the topological structures and coordinate environments of MOFs in the pyrolysis progress. Ceria catalysts with more defective sites can be formed by protection of the carbon skeleton in Ce-MOF-808 and Ce-BTC. These defects play an important role in the catalytic combustion. Thus, the catalysts perform with the activity sequence: $\mathrm{CeO}_{2}-\mathrm{MOF}-808>\mathrm{CeO}_{2}-\mathrm{BTC}>\mathrm{CeO}_{2}-\mathrm{UiO}-66 . \mathrm{CeO}_{2}-\mathrm{MOF}-808$ with the smallest particle size, the highest content of reactive oxygen species, and the greatest reductive properties, exhibited the best catalytic performance. Coordinate environments of MOFs are critical for the particle formation process. BTC as a ligand was more conducive to the maintenance of a skeleton than BDC during calcination. Surface properties of MOF precursors play an important role in the formation of oxides. The large surface area and abundant oxygen defects of $\mathrm{CeO}_{2}-\mathrm{MOF}-808$ originate from the porous structure of the MOF-808 precursor. 
Supplementary Materials: The following are available online at http://www.mdpi.com/2073-4344/9/8/682/s1, Figure S1: SEM images of Ce-MOF-808, Ce-BTC, and Ce-UiO-66 before calcination (a1, b1, c1), Ce-MOF-808-250, Ce-BTC-340 and Ce-UiO-66-320 after calcination at $250{ }^{\circ} \mathrm{C}, 340{ }^{\circ} \mathrm{C}$, and $320^{\circ} \mathrm{C}$, respectively $(\mathrm{a} 2, \mathrm{~b} 2, \mathrm{c} 2)$ and the corresponding final $\mathrm{CeO}_{2}-\mathrm{MOF}$ after calcination at $500{ }^{\circ} \mathrm{C}(\mathrm{a} 3, \mathrm{~b} 3, \mathrm{c} 3)$.

Author Contributions: W.S. (Wenjie Sun) designed and performed the experiments, analyzed the data, and wrote the paper; X.L. prepared the MOFs; Z.H. and C.S. designed the reactor system; H.X. and W.S. (Wei Shen) conceived the project and reviewed the paper.

Funding: This research was supported by the National Key R\&D Program of the Ministry of Science and Technology (Grant No. 2017YFB0602204), the National Natural Science Foundation of China (Grant No. 91645201), and the Shanghai Science and Technology Committee (Grant No. 14DZ2273900).

Conflicts of Interest: The authors declare no conflicts of interest.

\section{References}

1. Kampa, M.; Castanas, E. Human health effects of air pollution. Environ. Pollut. 2008, 151, 362-367. [CrossRef] [PubMed]

2. Wang, T.; Wei, X.L.; Ding, A.J.; Poon, C.N.; Lam, K.S.; Li, Y.S.; Chan, L.Y.; Anson, M. Increasing surface ozone concentrations in the background atmosphere of Southern China, 1994-2007. Atmos. Chem. Phys. 2009, 9 , 6217-6227. [CrossRef]

3. Hui, L.; Liu, X.; Tan, Q.; Feng, M.; An, J.; Qu, Y.; Zhang, Y.; Cheng, N. VOC characteristics, sources and contributions to SOA formation during haze events in Wuhan, Central China. Sci. Total Environ. 2019, 650, 2624-2639. [CrossRef] [PubMed]

4. Zhou, K.; Ma, W.; Zeng, Z.; Ma, X.; Xu, X.; Guo, Y.; Li, H.; Li, L. Experimental and DFT study on the adsorption of VOCs on activated carbon/metal oxides composites. Chem. Eng. J. 2019, 372, 1122-1133. [CrossRef]

5. Zhang, S.; You, J.; Kennes, C.; Cheng, Z.; Ye, J.; Chen, D.; Chen, J.; Wang, L. Current advances of VOCs degradation by bioelectrochemical systems: A review. Chem. Eng. J. 2018, 334, 2625-2637. [CrossRef]

6. Liotta, L.F. Catalytic oxidation of volatile organic compounds on supported noble metals. Appl. Catal. B Environ. 2010, 100, 403-412. [CrossRef]

7. Temerev, V.L.; Vedyagin, A.A.; Afonasenko, T.N.; Iost, K.N.; Kotolevich, Y.S.; Baltakhinov, V.P.; Tsyrulnikov, P.G. Effect of Ag loading on the adsorption/desorption properties of ZSM-5 towards toluene. React. Kinet. Mech. Catal. 2016, 119, 629-640. [CrossRef]

8. Behar, S.; Gomez-Mendoza, N.-A.; Gomez-Garcia, M.-A.; Swierczynski, D.; Quignard, F.; Tanchoux, N. Study and modelling of kinetics of the oxidation of VOC catalyzed by nanosized $\mathrm{Cu}-\mathrm{Mn}$ spinels prepared via an alginate route. Appl. Catal. A Gen. 2015, 504, 203-210. [CrossRef]

9. Carrillo, A.M.; Carriazo, J.G. Cu and Co oxides supported on halloysite for the total oxidation of toluene. Appl. Catal. B Environ. 2015, 164, 443-452. [CrossRef]

10. Piumetti, M.; Fino, D.; Russo, N. Mesoporous manganese oxides prepared by solution combustion synthesis as catalysts for the total oxidation of VOCs. Appl. Catal. B Environ. 2015, 163, 277-287. [CrossRef]

11. Garcia, T.; Agouram, S.; Sanchez-Royo, J.F.; Murillo, R.; Maria Mastral, A.; Aranda, A.; Vazquez, I.; Dejoz, A.; Solsona, B. Deep oxidation of volatile organic compounds using ordered cobalt oxides prepared by a nanocasting route. Appl. Catal. A Gen. 2010, 386, 16-27. [CrossRef]

12. Schilling, C.; Hess, C. Elucidating the Role of Support Oxygen in the Water-Gas Shift Reaction over Ceria-Supported Gold Catalysts Using Operando Spectroscopy. ACS Catal. 2019, 9, 1159-1171. [CrossRef]

13. Huang, N.; Geng, Y.; Xiong, S.; Huang, X.; Kong, L.; Yang, S.; Peng, Y.; Chen, J.; Li, J. The promotion effect of ceria on high vanadia loading NH3-SCR catalysts. Catal. Commun. 2019, 121, 84-88. [CrossRef]

14. Zhao, P.; Qin, F.; Huang, Z.; Sun, C.; Shen, W.; Xu, H. MOF-derived hollow porous Ni/CeO 2 octahedron with high efficiency for $\mathrm{N}_{2} \mathrm{O}$ decomposition. Chem. Eng. J. 2018, 349, 72-81. [CrossRef]

15. Feng, Z.; Ren, Q.; Peng, R.; Mo, S.; Zhang, M.; Fu, M.; Chen, L.; Ye, D. Effect of $\mathrm{CeO}_{2}$ morphologies on toluene catalytic combustion. Catal. Today 2019, 332, 177-182. [CrossRef]

16. Manuel Lopez, J.; Gilbank, A.L.; Garcia, T.; Solsona, B.; Agouram, S.; Torrente-Murciano, L. The prevalence of surface oxygen vacancies over the mobility of bulk oxygen in nanostructured ceria for the total toluene oxidation. Appl. Catal. B Environ. 2015, 174, 403-412. [CrossRef]

17. Hu, F.; Chen, J.; Peng, Y.; Song, H.; Li, K.; Li, J. Novel nanowire self-assembled hierarchical $\mathrm{CeO}_{2}$ microspheres for low temperature toluene catalytic combustion. Chem. Eng. J. 2018, 331, 425-434. [CrossRef] 
18. Jiao, L.; Wang, Y.; Jiang, H.-L.; Xu, Q. Metal-Organic Frameworks as Platforms for Catalytic Applications. Adv. Mater. 2018, 30. [CrossRef]

19. Zhao, W.; Zhang, Y.; Wu, X.; Zhan, Y.; Wang, X.; Au, C.-T.; Jiang, L. Synthesis of Co-Mn oxides with double-shelled nanocages for low-temperature toluene combustion. Catal. Sci. Technol. 2018, 8, 4494-4502. [CrossRef]

20. Luo, Y.; Zheng, Y.; Zuo, J.; Feng, X.; Wang, X.; Zhang, T.; Zhang, K.; Jiang, L. Insights into the high performance of Mn-Co oxides derived from metal organic frameworks for total toluene oxidation. J. Hazard. Mater. 2018, 349, 119-127. [CrossRef]

21. Wang, H.; Liu, M.; Guo, S.; Wang, Y.; Han, X.; Bai, Y. Efficient oxidation of o-xylene over $\mathrm{CeO}_{2}$ catalyst prepared from a Ce-MOF template: The promotion of $\mathrm{K}^{+}$embedding substitution. Mol. Catal. 2017, 436, 120-127. [CrossRef]

22. Chen, X.; Chen, X.; Yu, E.; Cai, S.; Jia, H.; Chen, J.; Liang, P. In situ pyrolysis of Ce-MOF to prepare $\mathrm{CeO}_{2}$ catalyst with obviously improved catalytic performance for toluene combustion. Chem. Eng. J. 2018, 344, 469-479. [CrossRef]

23. Lammert, M.; Glissmann, C.; Reinsch, H.; Stock, N. Synthesis and Characterization of New Ce(IV)-MOFs Exhibiting Various Framework Topologies. Cryst. Growth Des. 2017, 17, 1125-1131. [CrossRef]

24. Liu, K.; You, H.; Jia, G.; Zheng, Y.; Huang, Y.; Song, Y.; Yang, M.; Zhang, L.; Zhang, H. Hierarchically Nanostructured Coordination Polymer: Facile and Rapid Fabrication and Tunable Morphologies. Cryst. Growth Des. 2010, 10, 790-797. [CrossRef]

25. Lammert, M.; Wharmby, M.T.; Smolders, S.; Bueken, B.; Lieb, A.; Lomachenko, K.A.; De Vos, D.; Stock, N. Cerium-based metal organic frameworks with UiO-66 architecture: Synthesis, properties and redox catalytic activity. Chem. Commun. 2015, 51, 12578-12581. [CrossRef] [PubMed]

26. Chen, G.; Guo, Z.; Zhao, W.; Gao, D.; Li, C.; Ye, C.; Sun, G. Design of Porous/Hollow Structured Ceria by Partial Thermal Decomposition of Ce-MOF and Selective Etching. ACS Appl. Mater. Interfaces 2017, 9, 39594-39601. [CrossRef]

27. Isaeva, V.I.; Belyaeva, E.V.; Fitch, A.N.; Chernyshev, V.V.; Klyamkin, S.N.; Kustov, L.M. Synthesis and Structural Characterization of a Series of Novel Zn(II)-based MOFs with Pyridine-2, 5-dicarboxylate Linkers. Cryst. Growth Des. 2013, 13, 5305-5315. [CrossRef]

28. Yang, X.; Yu, X.; Lin, M.; Ma, X.; Ge, M. Enhancement effect of acid treatment on $\mathrm{Mn}_{2} \mathrm{O}_{3}$ catalyst for toluene oxidation. Catal. Today 2019, 327, 254-261. [CrossRef]

29. Agarwal, S.; Zhu, X.; Hensen, E.J.M.; Lefferts, L.; Mojet, B.L. Defect Chemistry of Ceria Nanorods. J. Phys. Chem. C 2014, 118, 4131-4142. [CrossRef]

30. Gao, W.; Zhang, Z.; Li, J.; Ma, Y.; Qu, Y. Surface engineering on $\mathrm{CeO}_{2}$ nanorods by chemical redox etching and their enhanced catalytic activity for CO oxidation. Nanoscale 2015, 7, 11686-11691. [CrossRef]

31. Wu, Z.; Li, M.; Howe, J.; Meyer, H.M., III; Overbury, S.H. Probing Defect Sites on $\mathrm{CeO}_{2}$ Nanocrystals with Well-Defined Surface Planes by Raman Spectroscopy and $\mathrm{O}_{2}$ Adsorption. Langmuir 2010, 26, 16595-16606. [CrossRef]

32. Lu, H.-F.; Zhou, Y.; Han, W.-F.; Huang, H.-F.; Chen, Y.-F. Promoting effect of $\mathrm{ZrO}_{2}$ carrier on activity and thermal stability of $\mathrm{CeO}_{2}$-based oxides catalysts for toluene combustion. Appl. Catal. A Gen. 2013, 464, 101-108. [CrossRef]

33. He, H.; Lin, X.; Li, S.; Wu, Z.; Gao, J.; Wu, J.; Wen, W.; Ye, D.; Fu, M. The key surface species and oxygen vacancies in $\mathrm{MnOx}(0.4)-\mathrm{CeO}_{2}$ toward repeated soot oxidation. Appl. Catal. B Environ. 2018, 223, 134-142. [CrossRef]

34. Wang, X.; Wu, J.; Wang, J.; Xiao, H.; Chen, B.; Peng, R.; Fu, M.; Chen, L.; Ye, D.; Wen, W. Methanol plasma-catalytic oxidation over $\mathrm{CeO}_{2}$ catalysts: Effect of ceria morphology and reaction mechanism. Chem. Eng. J. 2019, 369, 233-244. [CrossRef]

35. Alikin, E.A.; Vedyagin, A.A. High Temperature Interaction of Rhodium with Oxygen Storage Component in Three-Way Catalysts. Top. Catal. 2016, 59, 1033-1038. [CrossRef]

(C) 2019 by the authors. Licensee MDPI, Basel, Switzerland. This article is an open access article distributed under the terms and conditions of the Creative Commons Attribution (CC BY) license (http://creativecommons.org/licenses/by/4.0/). 